\title{
Information Desk
}

\section{우울 환자에게 유용한 문제해결치료}

\section{백정연}

한림대학교 강남성심병원 사회사업팀

\section{Problem Solving Therapy for Depressed Patients}

\section{Jung Yun Baek}

Department of Social Work, Hallym University Kangnam Sacred Heart Hospital, Seoul, Korea

\begin{abstract}
In a recent study, depression showed a negative effect on diabetes management, and comorbid disease was shown to increase risk of depression. This article introduces a problem solving therapy (PST) that can be applied to patients with depression in clinical settings. PST is a psychosocial intervention designed to reinforce an individual's ability to effectively cope with the stress of daily life to lower physical and mental stress and reduce related difficulties. The therapy is conducted in the following sessions: 1, Selecting and Defining Problems; 2, Setting Goals; 3, Finding Solutions; 4, Examining the Pros and Cons of Each Solution; 5, Choosing the Best Solution; 6, Creating and Implementing an Action Plan; 7, Evaluating the Results. PST is useful for depressed patients as it can address various problems experienced in daily life, such as economic problems, interpersonal difficulties, and psychosocial conditions. In addition, because the problem-solving process occur in 5 to 7 stages, the intervention period is relatively short compared to psychological therapy or counseling such as psychoanalysis. As depression has a negative influence on diabetes management as well as treatment of diabetic patients, sensitive assessment and timely intervention are necessary.
\end{abstract}

Keywords: Depression; Diabetes management; Diabetic patients; Problem solving therapy; Psychosocial intervention

This is an Open Access article distributed under the terms of the Creative Commons Attribution Non-Commercial License (http://creativecommons.org/licenses/by$\mathrm{nc} / 4.0 /$ ) which permits unrestricted non-commercial use, distribution, and reproduction in any medium, provided the original work is properly cited.

Copyright (C) 2021 Korean Diabetes Association 


$$
\text { 서론 }
$$

세계보건기구(World Health Organization)는 World Health Report (2001)를 통해 21세기 우울증이 모든 연령에서 나타 나는 질환 중 1 위를 차지할 것으로 예측하고 있다[1]. 또한 최근 연구에서는 우울이 당뇨병 환자의 관리에 부정적인 영 향을 미치며 동반질환의 상태가 우울증 위험을 증가시키는 것으로 조사되었다[2,3]. 성인을 대상으로 한 문제해결치료 (problem solving therapy, PST)의 우울 감소 효과는 충분 히 검증되어 왔다. PST는 우울, 불안, 자살생각 등의 정신건 강 문제뿐만 아니라 고혈압, 당뇨병, 비만, 암 등과 같은 신체 건강 문제로 어려움을 겪는 아동, 청소년, 중장년, 노인 및 그 가족을 대상으로 사회적 문제해결능력을 향상시키기 위하여 실시되어 왔고, 그 증상이 호전되고 스트레스를 낮추며 삶의 질이 향상됨이 여러 해외 선행연구들로부터 실증적으로 입증 되고 있다.

국내에서는 비행경험이 있는 청소년4], 비만 아동[5], 우울 성향을 지닌 여중생[6], 취업 스트레스가 큰 대학생[7], 알코올 중독자[8], 남성 도박중독자[9] 등을 대상으로 PST 프로그 램을 실행하고 그 효과성을 보고하고 있다. 이에 본 글에서 는 임상 현장에서 접하게 되는 우울을 가진 당뇨병 환자에게 유용하게 적용할 수 있는 PST를 소개하고자 한다.

\section{본론}

\section{1. 문제해결치료(PST)의 이해}

PST는 신체적·정신적 스트레스를 낮추고 미래에 발생할 수 있는 어려움을 감소시킬 수 있는 수단으로, 일상생활의 스 트레스에 효과적으로 대처하기 위한 개인의 능력을 강화하기 위해 고안된 심리사회적 개입이다[10]. PST는 일반적으로 인 지행동치료에 속하며, 내담자가 현재 경험하고 있는 정신적 건강과 신체적 건강의 문제를 완화하기 위한 목적으로 진행 된다. 이를 위해 PST에서는 경미한 스트레스(예: 만성적인 일 상적 문제들)와 중대한 스트레스(예: 외상적 사건) 모두에 효
과적으로 대처할 수 있는 내담자의 능력 강화에 초점을 맞춘 다. PST를 이해하기 위해서는 주요 개념인 문제해결, 문제, 해결책에 대한 이해가 필수적이다[11].

\section{1) 문제해결}

사회적 또는 실생활 문제해결(real-life problem solving)은 일상생활에서 만나게 되는 갑작스럽거나 만성적인 문제에 대 해 적응적인 대처방법을 확인하거나 발견하거나 발달시키려는 시도이다. 구체적으로 사람들의 다음의 사항을 바꾸고자 시 도하는 과정이다.

(1) 더 이상 문제가 나타나지 않도록 상황의 특성을 바꾸 려는 시도: 문제중심적 목표(problem-focused goals)라 고 불림

(2) 문제에 대한 부정적인 반응을 바꾸려는 시도: 정서중심 적 목표(emotion-focused goals)라고 불림

(3) 상황 그 자체와 문제에 대한 부적응적 정서적 반응을 바꾸려는 시도

2) 문제

문제는 다음과 같은 상황이 나타나거나 나타날 것으로 예 상되는 삶의 상황이다.

(1) 즉각적이거나 장기적인 부정적 결과를 예방하기 위해 적 응적 반응이 요구되는 상황(예: 실제적이거나 정서적인 평정상태를 유지하기 어려움)

(2) 다양한 장애물이나 장벽 때문에 상황을 경험하는 사람 에게 효과적인 반응이 즉시 분명하게 떠오르거나 이용 가능하지 않은 상황

문제를 야기하는 장애물이나 장벽에는 다음과 같은 요인 들이 포함된다.

(1) 낮섦(예: 새로운 환경으로의 이사)

(2) 모호함(예: 관계가 어떻게 진행되는지에 대한 혼란스러 움)

(3) 예측불가능성(예: 자신의 경력에 대한 통제권을 잃어버 림)

(4) 목표에 대한 갈등(예: 집을 살 것인지에 대한 의견 차이) 
(5) 수행기술의 결함(예: 직장동료와 의사소통을 하는 데 어려움)

(6) 자원의 부족(예: 할부금을 갚을 자금의 부족)

문제는 다양한 차원에서 일어난다.

(1) 순간적인 단일사건(예: 출근길에 지하철을 놓치거나 엘 리베이터의 문틈에 자동차 열쇠를 빠뜨리는 일)

(2) 연결되는 비슷하거나 관련된 사건들(예: 상사의 반복되 는 불합리한 요구들, 10대 자녀의 반복적인 늦은 귀가)

(3) 만성적이고 계속 진행되는 상황(예: 지속적인 통증, 지독 한 외로움, 심각한 질병)

\section{3) 해결책}

해결책은 개인이 가지고 있는 상황-특정적인 대처반응이나 반응패턴이 특정한 문제 상황에 적용되는 것이다. 해결책은 문제해결과정의 결과나 성과가 된다. 효과적인 해결책은 문제 해결을 위한 목표들을 성취하고 동시에 다른 긍정적인 결과 를 극대화시키고 부정적인 결과를 최소화시키는 것이다. 중요 한 성과에는 자신뿐만 아니라 다른 사람에 대한 결과, 장기 적 영향과 단기적 결과가 포함된다. 그러한 맥락에서 어떤 특 정한 해결책의 질이나 효과성은 각기 다른 사람들 또는 각기 다른 상황에 따라 크게 다를 수 있다.

\section{2. 문제해결치료(PST)의 회기구성}

- 회기의 수: PST는 짧게는 4회기부터 12회기 범위에서 진 행이 가능하다.

- 각 회기의 구성

-1회기: 문제 선정하고 문제 정의하기

-2회기: 목표 수립하기

-3 회기: 다양한 해결방안을 찾기

-4회기: 각각의 해결방안에 대한 장단점 검토하기

-5 회기: 최선의 해결방안 선택하기

-6회기: 실행계획을 만들어 해결방안을 실행하기

-7회기: 결과 평가하기

각 회기는 (1) 회기에서 다룰 주요 내용이 무엇인지 설명하
기, (2) 지난 회기에 제시된 과제(실행계획, 즐거운 활동하기) 점검하기, (3) 문제를 선정하고 해결방안을 선택한 후 실행계 획을 세우기, (4) 실행계획과 즐거운 활동하기를 과제로 해오 도록 재확인하기, (5) 회기를 마무리하기의 순서로 진행(1회기 는 총 60 분간 진행하며, 나머지 회기는 30 분씩 진행)한다.

\section{3. 문제해결치료(PST) 회기별 상담 내용}

\section{1) 1회기: 문제 선정하고 문제 정의하기}

본 프로그램은 사회적 문제해결능력을 향상시키기 위한 과 정이므로 '지금, 여기서' 직접 다룰 수 있는 문제, 실천이 가 능한 문제를 선정하도록 한다. (1) 현재 상태의 정서 상태나 몸 상태가 어떠한지 물어보는 것으로부터 출발한다. 그러한 감정이 들거나 신체적으로 불편함을 느끼게 된 순간, 사건, 상황 등을 이야기하는 과정을 통해 문제를 발견하도록 한 다. (2) 문제에 누가 관련되어 있는지, 어디서, 언제, 왜 문제가 일어나는지 문제와 관련된 객관적인 정보를 파악한다. (3) 단 순하고 명확하게 표현한다. (4) 잘못된 가정은 문제를 잘못 정의하게 하므로 실제 일어난 일(사실)과 추정하는 내용(가 정)을 구분하여 객관적인 사실을 구분해 낸다. (5) 화가 나면 상황을 격하게 과장되게 표현하는 경향이 있으므로 문제를 과장되지 않게, 명확하게 표현한다. (6) 문제가 너무 크다면, 다룰 수 있는 작은 문제로 나누고 다루도록 한다. (7) 문제 를 행동으로 관찰이 가능하고 측정이 가능한 측면에서 기술 함으로써 문제를 명확하고 객관적인 언어로 표현하도록 한 다[11].

\section{2) 2회기: 목표 수립하기}

목표는 성취가능하고 현실적인 것, 즉 작은 것부터, 노력과 시간을 들여서 빨리 쉽게 해결이 가능한 것부터 시작하도록 한다. 목표를 세운 다음에는 목표 달성에 주요한 장애물이 무엇인지 찾아보도록 한다. 장애물로는 (1) 새로움 또는 익 숙하지 않음, (2) 복잡함, (3) 상충되거나 모순되는 목표, (4) 본인의 능력이나 기술 부족, (5) 자원 부족, (6) 불확실성, (7) 감정적 어려움 등이 있다[11]. 


\section{3) 3회기: 다양한 해결방안을 찾기 위해 브레인스토밍 하기}

3 회기에서는 창의성을 발휘하여 브레인스토밍을 통해 다 양한 해결방안을 도출한다. 최상의 해결책을 찾기 위해서는 가능한 한 많은 해결방안들을 생각해내고, 그 중에서 최상 의 방안을 선택하는 것이다[11]. 클라이언트가 해결방안을 쉽 게 생각해내지 못할 경우 두 가지 방법을 활용할 수 있다. (1) 역할모델을 생각해본다. 이 문제를 이전에 경험했을 만한 사 람이 누구인지, 그 사람은 어떻게 해결했을지, 또는 내가 훌 륭하다고 생각하는 사람이라면 이 문제를 어떻게 해결할지를 생각해보는 것이다. (2) 매우 어렵거나 심각하거나 혹은 자주 경험하지 않는 문제인 경우에는 인터넷에서 검색을 하거나, 주요정보처에 정보를 문의해보거나, 전문가로부터 해결책에 대한 정보와 조언을 구해본다[12,13].

\section{4) 4 회기: 각각의 해결방안에 대한 장단점 검토하기}

효과적인 해결책을 찾기 위해 브레인스토밍을 통해 제시된 여러 해결방안들을 각각 훝어보고 심각하게 부정적 결과가 나오거나 실행하기 매우 어려운 방안을 제외할 수 있도록 해 결방안의 장단점을 살펴본다[11]. (1) 이 해결방안이 문제를 해 결하는가? (2) 이 해결방안이 나에게 가져오는 이득과 손실은 무엇인가? (3) 이 해결방안이 지닌 장점과 단점(시간, 노력, 돈, 타인과의 협력, 가족과 친구에게 미치는 영향 등)은 무엇인가? (4) 이 해결방안은 실제로 실행이 가능한가? (5) 이 해결방안 을 실행하는 데 장애물은 무엇인가? 등을 생각해본다[12,13]. 특히 대부분의 클라이언트들은 해결방안의 단점이나 그로 인 한 손해를 쉽게 먼저 생각해내는 경향이 많으므로, 장점과 이 득을 먼저 생각해보도록 독려한다.

\section{5) 5 회기: 최선의 해결방안 선택하기}

해결방안 각각에 대한 장단점을 비교하여 단점을 최소화하 면서 목표를 달성할 수 있는 해결책을 선택한다[11]. 이때 심 각하게 부정적인 결과를 가져오거나 실행하기 어려운 해결방 안은 제외시키도록 한다. 단점을 최소화하면서 목표를 달성 할 수 있는 해결방안을 선택하고 실행하기 쉬운지 여부보다
는 목표를 달성할 가능성이 높은 해결방안을 선택한다. 마지 막으로 선택된 해결방안을 실행할 경우 결과가 어떻게 나올지 를 예측해본다.

\section{6) 6회기: 실행계획을 만들어 해결방안을 실행하기}

선택된 해결방안을 실행하기 위해서 실행에 필요한 구체적 인 행동이나 작업, 또는 단계들을 세밀하게 생각해보고 실행 계획을 자세히 만든다. 실행계획에는 날짜, 시간, 필요한 도 구, 행동 리스트, 해야 할 말 스크립트, 타인의 도움 등이 포 함된다. 그리고 이러한 작업이나 단계들을 따라 실행함으로 써 문제가 충분히 해결될 것인지를 검토한다[13]. 성공적인 결 과를 가져오기 위해서는 실행계획을 세우는 데 서두르지 말 고 충분한 시간을 갖도록 한다. 클라이언트가 실행계획을 실 천하는 데 자신감이 없는 경우, 상담자와 클라이언트가 역할 을 맡아서 역할극을 함께 해보거나, 머릿속으로 실행계획을 시간의 흐름에 따라 상상해보거나, 또는 수행해야 할 단계 를 순서대로 자세하게 종이에 써보도록 한다. 이러한 과정에 서 해결방안에 대해 재평가가 가능하고, 해결방안을 수정하거 나 새로운 해결방안을 만들게 되기도 한다. 그리고 6회기 마 무리 시점에 상담자는 클라이언트에게 다음 회기까지 실행계 획에 따라 실천해오는 것을 과제로 부여하도록 한다.

\section{7) 7회기: 결과 평가하기}

6회기에서 세운 실행계획에 따라 실천하는 과제를 했는지 여부와 그 결과를 객관적으로 평가한다. 실행계획을 성공적 으로 실천했는지 물어보고, 실행계획을 실천함에 있어서 어떠 한 노력을 하였는지, 실천을 하면서 또는 실천한 후에 어떠한 기분이 들었는지 물어본다[13]. 실행계획을 실천함에 있어 목 표를 100\% 또는 일부 달성한 경우, 작은 성공이라도 칭찬하 고, 이러한 문제해결과정을 통해 문제해결기술이 향상되고 있 음을 강조한다. 그리고 성공적인 문제해결에 대해 자기보상 을 할 뿐만 아니라 실행하는 과정에서 들인 노력에 대해서도 자기보상을 하도록 한다. 만약, 실행계획을 실천하였지만 문 제해결에 실패하였다면, 실패도 문제해결과정 중의 하나이고 삶의 부분이며, 그러한 시도 속에 클라이언트가 문제에 대응 
하는 잠재력이 향상되고 있음을 설명함으로써 포기하지 않고 다시 시도해보거나 다른 대안을 찾아 실행하도록 독려하는 것이 필요하다.

\section{Tip: 즐거운 활동 과제 설명하기}

각 회기마다 다음 회기까지 즐거운 활동 과제가 부여될 것 임을 밝힌다. 즐거운 활동을 통해 긍정적인 정서를 경험하게 되고, 이러한 경험은 문제를 바라보는 태도를 바뀌게 하여 문 제해결을 성공적으로 이끄는 단초로 작용함을 설명한다[14]. 클라이언트 스스로 좋아하고 즐거운 활동을 생각해내고 실 천 가능한 범위 내에서 실행함으로써 긍정적인 정서를 경험 하게 되는데, 이는 문제를 바라보는 시각과 문제해결을 하는 양식에도 영향을 미친다. 따라서 즐거운 활동의 빈도를 증가 시키기 위해 매 회기 마지막에 즐거운 활동하기를 과제로 부 여하는 것을 권장한다.

\section{결론}

PST는 클라이언트에게 긍정적인 문제 지향을 촉진시키고 부정적인 문제 지향을 감소시키며, 합리적이고 계획적인 문제 해결양식을 '학습' 하여 실제 삶에서 적용할 수 있도록 돕는 다[15]. PST가 우울 환자에게 유용하다고 여겨지는 점은 첫 째, 심리사회적인 상태뿐만 아니라 경제적 문제나 대인관계로 인한 어려움 등과 같은 일상생활에서 경험하는 다양한 문제 들을 다룰 수 있다는 것과 둘째, 문제해결과정이 5 회기 또는 7회기로 구조화되어 있기 때문에 정신분석과 같은 심리치료나 상담에 비해 개입기간이 비교적 짧다는 것이다. 우울은 당뇨 병 환자의 당뇨관리뿐만 아니라 모든 질병치료에 있어 부정적 인 영향요인을 가지는 만큼 민감하게 사정하고 적시에 개입이 필요하다는 것을 강조하며 이 글을 마무리 하고자 한다.

\section{REFERENCES}

1. World Health Organization. The world health report 2001. Mental health: new understanding, new hope.
Geneva: World Health Organization; 2001.

2. Vuorilehto M, Melartin T, Isometsä E. Depressive disorders in primary care: recurrent, chronic, and comorbid. Psychol Med 2005;35:673-82.

3. Hur H, Choi J, Choi E, Koh J, Moon H. Mediating effects of perceived barriers on the relationship between depression and diabetes management self-efficacy in type 2 diabetes patients. Korean J Health Promot 2015;15:23543.

4. Yi MJ. The effects of a social problem-solving training on delinquent and non-delinquent adolescents. Korean J Couns Psychother 2006;8:71-91.

5. Cho MY, Lee HJ, Lee HJ, Park HS. The effect of problem solving group counseling on the index of obesity and health habits of obese children. J Korean Acad Nurs 2004;34:1224-33.

6. Um HY, Lee H, Lim Y. Effects of a problem-solving program on problem-solving ability, self-esteem, and depression for middle school girls. J Korean Acad Psychiatr Ment Health Nurs 2010;19:318-28.

7. Lee H. Problem-solving therapy for university students who experiencing job-seeking stress: case studies. Cognit Behav Ther 2018;18:285-312.

8. Choi YS. Efficacy of social problem-solving training program for alcoholics. Korean J Clin Psychol 2005;24:475-93.

9. You SH, Choi YS, Kim HS. A study of social problem solving among male pathological gamblers. Korean J Clin Psychol 2013;32:751-9.

10. Nezu AM, Greenfield AP, Nezu CM. Contemporary problem-solving therapy: a transdiagnostic intervention. In: Nezu CM, Nezu AM, eds. The Oxford handbook of cognitive and behavioral therapies. New York: Oxford University Press; 2015.

11. Nezu AM, Nezu CM, D’Zurilla TJ. Problem-solving 
therapy: a treatment manual. Lee HS, translator. Seoul: Hakjisa; 2016.

12. Lim YO. The effectiveness of problem-solving therapy program in suicide prevention for the depressed elderly living alone. Crisisonomy 2018;14:1-21.

13. Lim YO. A qualitative research on problem-solving therapy program process to manage depression among the elderly living alone. Crisisonomy 2019;15:1-24.
14. Yoon HS, Koo BM, Lee K, Lee JY. The effectiveness of problem-solving treatment on geriatric depression. J Korea Gerontol Soc 2010;30:871-94.

15. Yoon H, Kim Y, Choi K, Lim YO, Nam I, Kim W, et al. The effectiveness of problem-solving therapy program intervention in reducing depression of older cancer patients. Korean J Health Promot 2018;18:60-70. 